\title{
Danger is lurking everywhere: The relation between anxiety and threat perception abnormalities in normal children
}

Citation for published version (APA):

Muris, P. E. H. M., Luermans, J., Merckelbach, H. L. G. J., \& Maijer, B. N. (2000). Danger is lurking everywhere: The relation between anxiety and threat perception abnormalities in normal children. Journal of Behavior Therapy and Experimental Psychiatry, 31(2), 123-136. https://doi.org/10.1016/S00057916(00)00016-1

Document status and date:

Published: 01/01/2000

DOI:

10.1016/S0005-7916(00)00016-1

Document Version:

Publisher's PDF, also known as Version of record

Please check the document version of this publication:

- A submitted manuscript is the version of the article upon submission and before peer-review. There can be important differences between the submitted version and the official published version of record.

People interested in the research are advised to contact the author for the final version of the publication, or visit the DOI to the publisher's website.

- The final author version and the galley proof are versions of the publication after peer review.

- The final published version features the final layout of the paper including the volume, issue and page numbers.

Link to publication

\footnotetext{
General rights rights.

- You may freely distribute the URL identifying the publication in the public portal. please follow below link for the End User Agreement:

www.umlib.nl/taverne-license

Take down policy

If you believe that this document breaches copyright please contact us at:

repository@maastrichtuniversity.nl

providing details and we will investigate your claim.
}

Copyright and moral rights for the publications made accessible in the public portal are retained by the authors and/or other copyright owners and it is a condition of accessing publications that users recognise and abide by the legal requirements associated with these

- Users may download and print one copy of any publication from the public portal for the purpose of private study or research.

- You may not further distribute the material or use it for any profit-making activity or commercial gain

If the publication is distributed under the terms of Article $25 \mathrm{fa}$ of the Dutch Copyright Act, indicated by the "Taverne" license above, 


\title{
"Danger is lurking everywhere". The relation between anxiety and threat perception abnormalities in normal children ${ }^{\text {is }}$
}

\author{
Peter Muris $^{\mathrm{a}, *}$, Jaimie Luermans ${ }^{\mathrm{a}}$, Harald Merckelbach ${ }^{\mathrm{b}}$, \\ Birgit Mayer
}

${ }^{a}$ Department of Medical, Clinical, and Experimental Psychology, Maastricht University, P.O. Box 616, 6200 MD Maastricht, Netherlands

${ }^{\mathrm{b}}$ Department of Experimental Psychology, Maastricht University, Netherlands

${ }^{\mathrm{c}}$ Faculty of Social Sciences, Open University, Netherlands

Received 19 April 2000; received in revised form 28 July 2000; accepted 18 August 2000

\begin{abstract}
The present study examined the relation between anxiety and depression and threat perception abnormalities. Children were exposed to stories describing social situations. Some of the stories were ambiguous (i.e., these stories contained information that could be interpreted as threatening) whereas other stories were non-threatening (i.e., these stories contained no obvious trace of threat). From children's responses to the stories, several threat perception indices were derived. Children's level of anxiety and depression were assessed by means of self-report questionnaires. Results indicated that high levels of anxiety were accompanied by a high frequency of threat perception, high ratings of threat, a high frequency of threatening interpretations, high levels of negative feelings and cognitions, and an early detection of threat. Interestingly, significant associations between anxiety and threat perception abnormalities were not only observed in response to ambiguous stories but also in relation to non-threatening scenarios. Furthermore, depression was also connected with threat perception distortions. Even when controlling for anxiety levels, depression remained significantly related to threat frequency, threat ratings, and threat thresholds. (C) 2000 Elsevier Science Ltd. All rights reserved.
\end{abstract}

Keywords: Information processing; Perception of threat; Anxiety; Depression; Children

Guest Editor: John P. Forsyth.

* Corresponding author. Tel.: + 31-43-3881264; fax: + 31-43-36-0968.

E-mail address: p.muris@dep.unimaas.nl (P. Muris). 


\section{Introduction}

According to Kendall's (1985) theory of childhood anxiety, pathological fear and anxiety result from the chronic overactivity of schemas around themes of danger and death. These overactive schemas are assumed to chronically focus processing resources on threat-relevant information. Cognitive distortions play a prominent role in Kendall's theory. These distortions pertain to cognitive processes that are biased or erroneous, and therefore yield dysfunctional and maladaptive thoughts and behaviors (see for a comprehensive review, Daleiden \& Vasey, 1997).

One example of such a cognitive distortion is interpretation bias, which reflects anxious children's tendency to more readily interpret ambiguous situations as threatening. Support for the existence of interpretation bias in anxious children comes from a study by Barrett, Rapee, Dadds and Ryan (1996). These authors examined interpretations of ambiguous situations in anxiety disordered children, children with oppositional defiant disorder, and normal controls. Children were presented with vignettes of ambiguous situations and asked about what was happening during each situation. Then children were given two possible neutral outcomes and two possible threatening outcomes and asked which outcome was most likely to occur. Results showed that both anxious and oppositional children interpreted ambiguous stories as more threatening than did normal controls. Interestingly, anxious children more frequently chose avoidant outcomes, whereas oppositional children more often selected aggressive outcomes (see for similar findings, Chorpita, Albano \& Barlow, 1996; Bögels \& Zigterman, 2000). Employing a different approach, Hadwin, Frost, French and Richards (1997) investigated whether children's level of trait anxiety would be related to the interpretation of ambiguous stimuli. Children listened to homophones (i.e., words that sound the same but have two distinct meanings, such as dye versus die) and were asked to indicate the interpretation of a word by pointing to an appropriate picture. Results showed that levels of trait anxiety significantly predicted children's interpretation of homophones. More precisely, increases in levels of anxiety were positively associated with threatening interpretations. Altogether, these findings suggest that anxious children are more likely to interpret ambiguous information in a threatening way.

In two recent studies, Muris and colleagues (Muris, Merckelbach \& Damsma, 2000b; Muris et al., 2000a) found further support for the existence of cognitive distortions in anxious children. More specifically, in both studies, evidence was obtained for the presence of threat perception abnormalities in anxious children. In the first study (Muris et al., 2000b), socially anxious children $(n=28)$ and non-socially anxious children $(n=224)$ were exposed to ambiguous stories in which social situations were described. Children were told that some of these stories were scary, i.e., these stories would have a bad end, whereas other stories were not scary, i.e., these stories would have a happy end. Children were instructed to find out as quickly as possible whether the pertinent story was scary or not scary. Stories were read aloud sentence by sentence, and after each sentence children were asked whether they thought that the story would be scary or not scary. Results indicated that socially anxious children needed to hear fewer sentences before deciding that an ambiguous 
story was threatening compared to non-anxious control children. The Muris et al. (2000b) study further showed that socially anxious children more frequently perceived threat while listening to the stories, more often interpreted the complete story as threatening, and displayed higher levels of negative feelings and cognitions in relation to the stories than control children.

In the second study (Muris et al., 2000a) which relied on a highly similar design, 105 normal school children were confronted with three types of stories: social anxiety stories, separation anxiety stories, and generalized anxiety stories. Again, high levels of anxiety (as measured by questionnaires of anxiety disorders symptoms and trait anxiety) were found to be accompanied by an early detection of threat, high frequencies of threat perception and threat interpretation, and high levels of negative feelings and cognitions. Furthermore, findings seemed to suggest that these threat perception distortions were not specific for the various types of anxiety symptoms. That is to say, no support was found for the idea that children with high levels of a specific type of anxiety symptoms (e.g., those associated with social phobia) particularly show threat perception abnormalities in relation to a specific type of stories (i.e., social anxiety stories). In fact, results tentatively indicated that threat perception distortions were predominantly mediated by children's level of general anxiety (e.g., trait anxiety). In a discussion of these findings, Muris et al. (2000a) posited that the absence of an anxiety disorder-specific effect on threat perception indices was probably due to the fact that the comorbidity between anxiety disorders symptoms in children is rather high. In particular, symptoms of separation anxiety and generalized anxiety are frequently found to be related to a broad range of other anxiety disorders symptoms (Last, Hersen, Kazdin, Finkelstein \& Strauss, 1987; Last, Strauss \& Francis, 1987).

The present study was set up in an attempt to further investigate the relation between anxiety and threat perception abnormalities. Normal school children $(N=76)$ first completed three self-report measures: a specific scale for assessing social anxiety (i.e., the Social Anxiety Scale for Children - Revised [SASC-R]; La Greca $\&$ Stone, 1993), an index of trait anxiety, and a measure of depression. Next, children were exposed to social stories and instructed to find out as fast as possible whether the stories were scary or not scary. In this way, the threshold and frequency of threat perception were measured. Children were also asked to tell how each story would end (threat interpretation) and to judge how they would feel and think when actually confronted with these situations. All stories depicted social situations, as social anxiety seems to be an anxiety problem with less comorbidity than separation anxiety and generalized anxiety (see supra; cf., Muris et al., 2000a). There were three ambiguous stories (i.e., these stories contained information that could possibly interpreted as threatening), and three non-threatening versions of these stories (i.e., these stories described the same social situations but they were rewritten in such way that they contained no trace of threat). Non-threatening stories were included to examine whether anxiety was even associated with threat perception abnormalities in response to neutral information.

The relation between anxiety and threat perception abnormalities was examined in two ways. First, correlations were computed between social anxiety (SASC-R) and trait anxiety and threat perception indices. Second, partial correlations were 
computed between social anxiety and trait anxiety, on the one hand, and threat perception indices, on the other hand, while holding the other constant. These analyses were carried out in order to investigate the domain-specificity of threat perception abnormalities. When correlations between social anxiety and threat perception indices hold when controlling for trait anxiety, this would provide support for the notion that threat perception abnormalities are specific for this particular domain of anxiety symptoms. On the other hand, when correlations between trait anxiety and threat perception indices survive when holding social anxiety constant, this would point in the direction of a general anxiety effect.

An additional purpose of this study was to examine the relation between depression and threat perception abnormalities. Research has shown that depression is associated with facilitated processing of negative information (e.g., Teasdale, 1983) and there is now some evidence that this is not only true for the retrieval of memories, but also for the prediction of future events (MacLeod \& Byrne, 1996). Thus, it may well be the case that children with high levels of depression more easily perceive threat in hypothetical stories as they have the tendency to expect a negative outcome.

\section{Method}

\subsection{Participants}

Seventy-six primary school children (35 boys and 41 girls) were recruited from a regular primary school ('De Schans') in Maastricht, The Netherlands. All children of grades 3-6 and their parents were informed about the study by means of a letter that also invited them to participate. Fifty-one percent of the children and parents responded to this mailing and signed the informed consent form (no effort was made to contact the non-responders for a second time). The children who participated in the study had a mean age of $10.4(S D=1.2$, range: $8-13$ yr).

\subsection{Questionnaires}

The SASC-R (La Greca \& Stone, 1993) is a self-report measure that has been developed to assess social evaluative anxiety and social avoidance. The scale consists of 18 items (e.g., "I worry about what other kids say about me", "I get nervous when I talk to new kids", and "I feel shy even with kids I know very well") that are scored on a 5-point Likert scale ranging from $1=$ not at all to $5=$ all the time. A SASC-R total score was obtained by summing scores on all items. The psychometric properties of the SASC-R with primary school children are satisfactory: Internal consistency (with a Cronbach's alpha between 0.80 and 0.90 for the total score) and test-retest reliability (with a test-retest correlation of 0.67 for the total score) were sufficient to good (La Greca, Dandes, Wick, Shaw \& Stone, 1988; La Greca \& Stone, 1993). Furthermore, support has been found for the discriminant validity of the scale: In a sample of children with anxiety disorders, scores on the SASC-R differentiated children with and without a social-based anxiety disorder (Ginsburg, La Greca \& Silverman, 1998). 
The trait version of the State-Trait Anxiety Inventory for Children (STAIC; Spielberger, 1973) is a reliable and valid measure of general anxiety (e.g., Stallings \& March, 1995). The scale contains 20 items (e.g., "I am scared", "I feel troubled", and "I worry too much") that are rated on a 3-point scale: $1=$ almost never, $2=$ sometimes, or $3=$ often. STAIC scores range between 20 and 60 with higher scores reflecting higher levels of trait anxiety.

The Depression Questionnaire for Children (DQC; De Wit, 1987) is a brief measure of childhood depression that consists of nine items (e.g., "I feel depressed lately", "When something bad happens, I often think it is my fault", and "I don't sleep well lately"). Each item is scored on a 3-point scale: $1=$ not true, $2=$ somewhat true, and $3=$ very true. DQC scores vary between 9 and 27 with higher scores reflecting higher levels of depression. The psychometric properties are sound (with Cronbach's alpha generally exceeding 0.80 and a test-retest correlation in the 0.70 range) and there is evidence showing that the DQC satisfactorily discriminates between children with and without depressive symptoms (Meijer, Mellenbergh \& De Wit, 1986).

\subsection{Stories}

Six audiotaped, hypothetical stories of social situations were used (see the appendix). As mentioned earlier, there were three ambiguous stories (i.e., asking other children to come to your birthday party, encountering a group of unfamiliar children, and meeting a child of new neighbors) and three non-threatening versions of these stories. A pilot study that was carried out with a separate group of 40 school children (St. Aloysius school) revealed that ambiguous stories were indeed rated as more threatening than the non-threatening stories, means being $4.7(S D=2.6), 5.1$ $(S D=2.7)$, and $5.6(S D=2.6)$ versus $1.9(S D=1.7), 1.6(S D=0.9)$, and $1.4(S D=1.0)$, respectively (all $t \mathrm{~s}>5.0, p \mathrm{~s}<0.001$ ). Children received the following general instruction:

In a moment, I am going to read you a number of brief stories. Some stories are scary: this means that these stories will have a bad end. Some stories are not scary: this means that these stories will have a good end. You have to try to guess as quickly as possible whether the story that I read is a scary story which will have a bad end, or a non-scary story which will have a good end. I will read you each story sentence by sentence and after each sentence I will ask you whether you think that the story is scary or non-scary. Once you have told me that you think the story will be scary, you still may change your opinion after the next sentence.

Each story consisted of five sentences. After reading each sentence, the child was asked: "What do you think? Is this going to be a scary or a non-scary story?" Two scores were derived from children's answers to this question. First, for each story, the threshold of threat perception was established. This threshold score was defined as the moment at which the child first began to perceive the story as scary. When a child indicated that the story was scary after reading the first sentence, the threshold score 
was 1 , when a child indicated that the story was scary after the second sentence, the threshold score was 2 , etc. When a child still indicated that the story was non-scary after the fifth sentence, the threshold was scored as 6 . Thus, the lower the threshold score, the less information a child needed to perceive threat. Second, for each story, the number of sentences after which children indicated the story to be scary was summed to yield the frequency of threat perception. This variable provided additional information since children were allowed to change their opinion after hearing a new sentence of the story.

After each sentence of the story, threat ratings were obtained. Each time the child indicated the story to be scary, he or she was asked to predict how threatening the story was going to be on a 10 -point Likert scale $(1=$ almost not, $10=$ very much $)$. This threat rating was scored as 0 when children indicated the story was nonscary after hearing a sentence. For each story, a mean threat rating score was calculated.

To measure interpretation bias, the story was then read out to the children for a second time without any interruptions. Children were asked: "What do you think will happen in this situation?" Children's answers were written down word-by-word, and then rated by a blind rater who judged whether children had interpreted the pertinent story as either threatening or non-threatening. A second blind rater judged the answers of 20 randomly selected children. Raters agreed on $92.5 \%$ of the answers, resulting in an overall kappa of 0.85 .

Finally, children were asked: "How would you feel if you were in this situation?" and rated the following feelings and cognitions scales: 1. I am scared, 2. I am shy, 3. I don't know what to do, 4. I am worried that this will end badly. Each scale had to be scored on a 5-point scale with $1=$ not at all, $2=$ a little, $3=$ somewhat, $4=$ pretty much, and $5=$ very much. Scores on the four scales were summed to compute a total score for each story.

For each type of story (i.e., ambiguous and non-threatening), threat perception scores were combined. Threat threshold, threat rating, and feelings and cognitions scores were all averaged (the ranges for these indices per story type were 1-6, 0-10, and 4-20, respectively), whereas threat frequency and threat interpretation scores were summed (ranges were 0-15 and 0-3, respectively; see Table 1).

\subsection{Procedure}

Children first completed the self-report questionnaires (SASC-R, STAIC, and DQC). This was done in their classrooms in the presence of a teacher and a research assistant who ensured confidential and independent responding and who provided assistance to the children if necessary. In the two weeks following the administration of the questionnaires, children were tested individually in a separate room at school. The research assistant who carried out the interviews was blind to children's questionnaire scores. Ambiguous and non-threatening stories were presented by audiotape in a fixed, alternating order. To control for order effects, each child started at a different point within this order. 
Table 1

Definitions of threat perception indices and the range of scores on these measures

\begin{tabular}{|c|c|c|c|}
\hline Threat index & Definition & $\begin{array}{l}\text { Range per } \\
\text { story }\end{array}$ & $\begin{array}{l}\text { Range per } \\
\text { story type }\end{array}$ \\
\hline Threat threshold ${ }^{\mathrm{a}}$ & $\begin{array}{l}\text { The moment (i.e., sentence) at which the child } \\
\text { begins to perceive the story as threatening }\end{array}$ & $1-6$ & $1-6$ \\
\hline Threat frequency & $\begin{array}{l}\text { The number of sentences after which the child } \\
\text { indicates that the story is going to be threatening }\end{array}$ & $0-5$ & $0-15$ \\
\hline Threat ratings & $\begin{array}{l}\text { Prediction (after hearing each sentence) of how } \\
\text { threatening the story is going to be }\end{array}$ & $0-10$ & $0-10$ \\
\hline Threat interpretation & $\begin{array}{l}\text { Threatening interpretation of the child after } \\
\text { hearing the whole story }\end{array}$ & $0-1$ & $0-3$ \\
\hline Feelings and cognitions & $\begin{array}{l}\text { Ratings of how the child would think and feel } \\
\text { when actually confronted with situation }\end{array}$ & $4-20$ & $4-20$ \\
\hline
\end{tabular}

${ }^{a}$ High threat threshold scores are indicative for low levels of threat perception. For all other variables, higher scores reflect higher levels of threat perception.

\section{Results}

\subsection{General results}

Table 2 presents mean scores on questionnaires and threat perception indices for the total group and for boys and girls separately, and reliability coefficients for the various measures. Three conclusions can be drawn from this table. First of all, significant gender differences were found for SASC-R $[t(74)=2.7, p<0.01]$, STAIC $[t(74)=2.5, p<0.05]$, DQC $[t(74)=3.1, p<0.005]$, and feelings and cognitions scores in relation to ambiguous stories $[t(74)=2.1, p<0.05]$. As can be seen, girls displayed higher levels of social anxiety, trait anxiety, and depression, and evaluated ambiguous stories as more threatening than did boys. Second, paired $t$-tests revealed higher threat perception scores for ambiguous stories compared to non-threatening stories [all $t(74) \mathrm{s}>10.0, p \mathrm{~s}<0.001]$. Third and finally, all questionnaires and threat perception indices were found to be reliable in terms of inter-rater agreement (threat interpretation) and internal consistency (questionnaires and all other threat perception indices).

\subsubsection{Correlations between social anxiety, trait anxiety, and depression, and threat perception abnormalities}

Table 3 shows correlations (corrected for gender) between social anxiety (SASC-R), trait anxiety (STAIC), and depression (DQC), on the one hand, and threat perception indices, on the other hand. As expected, positive correlations were found between social anxiety and trait anxiety scores and threat frequency, threat ratings, threat interpretation, and negative feelings and cognitions, while negative correlations emerged between anxiety scores and threat thresholds. Thus, high levels of social anxiety and trait anxiety were accompanied by a high frequency of threat perception, 
Table 2

Mean scores (standard deviations), gender differences, and reliability coefficients for the various measures that were used in the present study ${ }^{\mathrm{a}}$

\begin{tabular}{lcccc}
\hline & Total group $(N=76)$ & Boys $(n=35)$ & Girls $(n=41)$ & Reliability \\
\hline Questionnaires & & & & \\
SASC-R & $38.0(9.6)$ & $34.9(9.0) \mathrm{a}$ & $40.6(9.4) \mathrm{b}$ & 0.85 \\
STAIC & $34.5(5.9)$ & $32.7(4.8) \mathrm{a}$ & $36.0(6.4) \mathrm{b}$ & 0.77 \\
DQC & $12.4(3.3)$ & $11.3(3.1) \mathrm{a}$ & $13.5(3.1) \mathrm{b}$ & 0.74 \\
Threat perception & & & & \\
Non-threatening stories & & & & \\
Threat threshold & $5.0(1.2)$ & $4.9(1.3) \mathrm{a}$ & $5.0(1.1) \mathrm{a}$ & 0.61 \\
Threat frequency & $1.8(2.1)$ & $1.8(2.0) \mathrm{a}$ & $1.7(2.2) \mathrm{a}$ & 0.72 \\
Threat ratings & $0.5(0.6)$ & $0.5(0.6) \mathrm{a}$ & $0.5(0.7) \mathrm{a}$ & 0.72 \\
Threat interpretation & $0.4(0.7)$ & $0.5(0.7) \mathrm{a}$ & $0.4(0.7) \mathrm{a}$ & 0.74 \\
Feelings and cognitions & $6.4(1.8)$ & $6.2(1.8) \mathrm{a}$ & $6.6(1.8) \mathrm{a}$ & 0.84 \\
Ambiguous stories & & & & \\
Threat threshold & $2.9(1.0)$ & $3.0(1.2) \mathrm{a}$ & $2.8(0.8) \mathrm{a}$ & 0.70 \\
Threat frequency & $8.5(2.8)$ & $8.2(3.2) \mathrm{a}$ & $8.8(2.4) \mathrm{a}$ & 0.77 \\
Threat ratings & $3.1(1.6)$ & $3.1(1.7) \mathrm{a}$ & $3.2(1.5) \mathrm{a}$ & 0.88 \\
Threat interpretation & $2.3(0.9)$ & $2.2(1.0) \mathrm{a}$ & $2.3(0.8) \mathrm{a}$ & 0.72 \\
Feelings and cognitions & $10.5(3.2)$ & $9.7(3.1) \mathrm{a}$ & $11.3(3.2) \mathrm{b}$ & 0.90 \\
\hline
\end{tabular}

${ }^{\text {a }}$ SASC-R $=$ Social Anxiety Scale for Children - Revised, STAIC = trait anxiety version of the State-Trait Anxiety Inventory for Children, DQC $=$ Depression Questionnaire for Children. Means in the same row that do not share the same letters differ at $p<0.05$.

${ }^{\mathrm{b}}$ For most variables Cronbach's alphas were calculated, for threat interpretation measures Cohen's kappa was used.

high ratings of threat, a high frequency of threatening interpretations, high levels of negative feelings and cognitions, and an early detection of threat. Interestingly, correlations between anxiety scores and threat perception indices were highly similar for both types of stories. More precisely, even in the case of non-threatening stories, anxiety appeared to be associated with threat perception abnormalities.

As can be seen in Table 3, depression was also significantly related to most threat perception indices. In particular, high levels of depression were associated with a high frequency of threat perception, high levels of negative feelings and cognitions, and an early detection of threat.

\subsection{Threat perception abnormalities: Domain-specific or general anxiety effect?}

Partial correlations were calculated separately for social anxiety (SASC-R) and trait anxiety (STAIC) with threat perception indices while holding the other constant. Results showed that when controlling for trait anxiety, social anxiety remained significantly related to most of the threat perception measures. However, when controlling for social anxiety, trait anxiety was no longer significantly connected to 
Table 3

Correlations (corrected for gender) between social anxiety (SASC-R), trait anxiety (STAIC), and depression (DQC) on the one hand, and threat perception indices on the other hand $(N=76)^{\mathrm{a}}$

\begin{tabular}{lrcc}
\hline & SASC-R & STAIC & DQC \\
\hline Threat perception & & & \\
Non-threatening stories & & & $-0.41^{\mathrm{b}}$ \\
Threat threshold & $-0.38^{\mathrm{b}}$ & $-0.39^{\mathrm{b}}$ & $0.35^{\mathrm{b}}$ \\
Threat frequency & $0.46^{\mathrm{b}}$ & $0.38^{\mathrm{b}}$ & $0.35^{\mathrm{b}}$ \\
Threat ratings & $0.49^{\mathrm{b}}$ & $0.37^{\mathrm{b}}$ & 0.15 \\
Threat interpretation & $0.31^{\mathrm{c}}$ & 0.20 & $0.30^{\mathrm{c}}$ \\
Feelings and cognitions & $0.52^{\mathrm{b}}$ & $0.48^{\mathrm{b}}$ & \\
Ambiguous stories & & & $-0.34^{\mathrm{b}}$ \\
Threat threshold & $-0.36^{\mathrm{b}}$ & $-0.28^{\mathrm{c}}$ & $0.27^{\mathrm{c}}$ \\
Threat frequency & $0.38^{\mathrm{b}}$ & $0.27^{\mathrm{c}}$ & 0.23 \\
Threat ratings & $0.40^{\mathrm{b}}$ & $0.27^{\mathrm{c}}$ & 0.23 \\
Threat interpretation & $0.33^{\mathrm{b}}$ & $0.36^{\mathrm{b}}$ & $0.29^{\mathrm{c}}$ \\
Feelings and cognitions & $0.44^{\mathrm{b}}$ & $0.43^{\mathrm{b}}$ & \\
\hline
\end{tabular}

${ }^{\text {a }}$ SASC-R = Social Anxiety Scale for Children - Revised, STAIC = trait anxiety version of the State-Trait Anxiety Inventory for Children, DQC $=$ Depression Questionnaire for Children.

${ }^{\mathrm{b}} p<0.005$.

${ }^{\mathrm{c}} p<0.05$.

threat perception indices (see Table 4). These findings provide support for the idea that threat perception abnormalities were domain-specific and not only mediated by levels of general anxiety.

\subsection{Threat perception abnormalities: a pure anxiety phenomenon?}

To examine whether threat perception abnormalities concern a pure anxiety phenomenon, partial correlations were computed for social anxiety (SASC-R) and depression (DQC) with threat perception indices while holding the other constant. As can be seen in Table 5, when controlling for depression, social anxiety remained significantly linked to all threat perception indices. When holding social anxiety constant, most correlations between depression and threat perception indices clearly attenuated. However, depression remained significantly related to threat frequency, threat ratings (non-threatening stories) and threat thresholds (both types of stories). In other words, even when controlling for anxiety, depression to some extent predicted threat perception abnormalities.

\section{Discussion}

The present study examined the relation between anxiety and depression and threat perception abnormalities. Children were exposed to stories describing social situations. Some of the stories were ambiguous (i.e., these stories contained information 
Table 4

Partial correlations (controlling for gender) calculated separately for social anxiety (SASC-R) and trait anxiety (STAIC) with threat perception indices while holding the other one constant $(N=76)^{\mathrm{a}}$

SASC-R controlling for trait anxiety
STAIC controlling for social anxiety

Threat perception

Non-threatening stories

Threat threshold

$-0.18$

$0.31^{\mathrm{b}}$

$0.36^{\mathrm{c}}$

$0.25^{\mathrm{b}}$

$0.32^{\mathrm{b}}$

$-0.24^{\mathrm{b}}$

$0.28^{\mathrm{b}}$

$0.31^{\mathrm{b}}$

0.14

$0.24^{\mathrm{b}}$

$$
\begin{array}{r}
-0.20 \\
0.11 \\
0.07 \\
-0.01 \\
0.21
\end{array}
$$

$$
\begin{array}{r}
-0.07 \\
0.02 \\
0.01 \\
0.20 \\
0.21
\end{array}
$$

${ }^{\text {a }}$ SASC-R = Social Anxiety Scale for Children - Revised, STAIC $=$ trait anxiety version of the State-Trait Anxiety Inventory for Children.

${ }^{\mathrm{b}} p<0.05$.

${ }^{\mathrm{c}} p<0.005$.

Table 5

Partial correlations (controlling for gender) calculated separately for social anxiety (SASC-R) and depression (DQC) with threat perception indices while holding the other one constant $(N=76)^{\mathrm{a}}$

SASC-R controlling

for depression
DQC controlling for social anxiety

\section{Threat perception}

Non-threatening stories

Threat threshold

Threat frequency

Threat ratings

$-0.31^{\mathrm{b}}$

$0.41^{\mathrm{c}}$

$0.44^{\mathrm{c}}$

$0.29^{\mathrm{b}}$

$0.48^{\mathrm{c}}$

$$
\begin{array}{r}
-0.34^{\mathrm{c}} \\
0.27^{\mathrm{b}} \\
0.26^{\mathrm{b}}
\end{array}
$$

Feelings and cognitions

$-0.29^{\mathrm{b}}$
$0.33^{\mathrm{c}}$
$0.36^{\mathrm{c}}$
$0.29^{\mathrm{b}}$
$0.39^{\mathrm{c}}$

$$
\begin{gathered}
-0.27^{\mathrm{b}} \\
0.19 \\
0.13 \\
0.15 \\
0.21
\end{gathered}
$$

${ }^{\text {a }}$ SASC-R = Social Anxiety Scale for Children - Revised, DQC = Depression Questionnaire for Children. ${ }^{\mathrm{b}} p<0.05$.

${ }^{\mathrm{c}} p<0.005$. 
that could be interpreted as threatening) whereas other stories were non-threatening (i.e., these stories contained no trace of threat). From children's responses to the stories, a number of threat perception indices were derived. Children's level of anxiety and depression were assessed by means of self-report questionnaires. The main results can be summarized as follows. First, high levels of anxiety were associated with a high frequency of threat perception, high ratings of threat, a high frequency of threatening interpretations, high levels of negative feelings and cognitions, and an early detection of threat. Second, evidence was found for the notion that threat perception abnormalities were domain-specific and not only mediated by levels of general anxiety. That is, when controlling for trait anxiety, social anxiety remained a significant predictor of threat perception distortions in response to stories depicting social situations. However, when controlling for social anxiety, trait anxiety was no longer associated with threat perception abnormalities. Third, significant associations between anxiety and threat perception abnormalities were not only observed in response to ambiguous stories but also in relation to non-threatening scenarios. Fourth and finally, depression was also connected with threat perception distortions. More specifically, even when controlling for anxiety levels, depression remained significantly related to threat frequency, threat ratings, and threat thresholds.

The present findings replicate those of our previous studies (Muris et al., 2000a, b) showing that anxiety is accompanied by threat perception abnormalities. The higher children's level of anxiety, the more frequently and easily they perceived threat in ambiguous scenarios. Interestingly, anxiety was also related to threat perception abnormalities in response to non-threatening stories. This result suggests that even when confronted with non-threatening information, anxious children are biased to expect a threatening outcome. Thus, the present data not only indicate that anxiety is accompanied by threat perception abnormalities, but also show that these distortions surface under relatively benign circumstances.

Threat perception abnormalities as documented in the present study should not be considered as the cause of anxiety problems in children. Rather they should be viewed as an epiphenomenon of high levels of anxiety that make children more sensitive to potentially threatening information. Thus, it seems plausible that these threat perception distortions play a role in the continuation of anxiety complaints in children. As such, the correction of such threat perception abnormalities may be an important component in the treatment of children with anxiety disorders. For example, cognitive-behavioral treatment (e.g., Ollendick \& King, 1998) teaches children to recognize threat perception distortions and consciously try to combat them by using more adaptive self-talk.

The current study seems to indicate that anxiety was more strongly associated with threat perception abnormalities than depression. That is, when controlling for levels of depression, all correlations between anxiety and threat perception indices remained substantial and significant. In contrast, when controlling for anxiety, correlations between depressive symptoms and threat perception clearly attenuated. Nevertheless, depression scores were still significantly associated with some of the threat perception measures (i.e., threat threshold, threat frequency, and threat ratings). Previous studies in child and adult samples have shown that depression can best be conceptualized as 
a combined state of high levels of negative affectivity and low levels of positive affectivity (e.g., Brown, Chorpita \& Barlow, 1998; Chorpita, Plummer \& Moffit, in press; Clark \& Watson, 1991; Watson, Clark \& Carey, 1988). MacLeod and Byrne (1996) found tentative evidence that this affective constellation influences future thinking. More specifically, high levels of depression would go with greater anticipation of negative future events and reduced anticipation of positive future events. It may well be the case that depression was related to some of the threat perception indices through its high negative affectivity and low positive affectivity components.

It should be acknowledged that the present study suffers from various limitations. To begin with, children were explicitly instructed that some of the stories would be scary and so, presumably, they felt demand to judge some stories to be threatening. Thus, it would be interesting to examine whether the observed threat perception abnormalities also occur when children receive more neutral instructions (i.e., when they are not told that "some stories will be scary"). Furthermore, stories were presented in a fixed, alternating order. While this was a suitable method of correcting for systematic order effects, one could argue that children were able to anticipate the valence of the stories before it was presented. Finally, the study was carried out in a relatively small sample of normal children and, of course, it will be important to replicate these findings in a clinical setting with anxiety disordered children. Despite these shortcomings, the present findings can be taken as further evidence for the presence of information processing abnormalities in children with anxiety problems. Anxious children seem to have a motto that can best be summarized as "Danger is lurking everywhere" which manifests itself in threat perception abnormalities that even occur in relatively non-threatening situations. It is likely that these distortions play a role in the maintenance of anxiety disorders in children and that they should be considered as relevant targets for treatment.

\section{Acknowledgements}

Teachers, staff, and children of primary schools 'De Schans' and 'St. Aloysius' in Maastricht, The Netherlands are thanked for their participation in the present study.

\section{Appendix A}

(Stories that were used in the current study)

\section{Story 1 (Ambiguous)}

1. Next week is your birthday and you want to organize a birthday party.

2. Mother has told you that you may invite all of your classmates.

3. The teacher allows you to speak to your class so that you can invite everyone.

4. Standing in front of the class, you hear some of your classmates laughing.

5. When you sit down again, everyone suddenly begins to laugh about you. 


\section{Story 2 (Non-threatening)}

1. You have new neighbors with a nice boy/girl (opposite sex) of your age.

2. You have already played once with him/her.

3. When you are outside you see the boy/girl waving hello from behind the window.

4. $\mathrm{He} / \mathrm{she}$ comes out of the house.

5. $\mathrm{He} / \mathrm{she}$ asks whether you can come to play inside.

\section{Story 3 (Ambiguous)}

1. You are going on holiday. Your parents have told you that you are going to a campsite where there will be a lot of other children.

2. You have just arrived and you walk around the campsite to see where everything is.

3. You see a group of children. They are yelling and pushing each other.

4. When you pass them, they suddenly stop and look at you.

5. They begin to talk to you.

\section{Story 4 (Non-threatening)}

1. Next week is your birthday and you want to organize a birthday party.

2. You have made a list of children you want to invite.

3. The children who are invited have told you that they will certainly come.

4. During the break at school, you see some of the invited children.

5. They come to you and say that they are looking forward to your party.

\section{Story 5 (Ambiguous)}

1. You have new neighbors with a boy/girl (opposite sex) of your age.

2. You have heard from other children that this boy/girl is always arguing.

3. When you are outside you see the boy/girl looking at you from behind the window.

4. $\mathrm{He} / \mathrm{she}$ comes out of the house.

5. He/she walks towards you.

\section{Story 6 (Non-threatening)}

1. You are going on holiday. Your parents have told you that you are going to a campsite where there will be a lot of other children.

2. You have just arrived and you walk around the campsite to see where everything is.

3. You see a group of children. One of these children is a friendly classmate from school.

4. Your classmate says: "Hey, how nice that you are also on this campsite!"

5. The children friendly ask you to join the group and to play along.

\section{References}

Barrett, P. M., Rapee, R. M., Dadds, M. R., \& Ryan, S. M. (1996). Family enhancement of cognitive style in anxious and aggressive children: Threat bias and the FEAR effect. Journal of Abnormal Child Psychology, 24, 187-203.

Bögels, S. M., \& Zigterman, D. (2000). Dysfunctional cognitions in children with social phobia, separation anxiety disorder, and generalized anxiety disorder. Journal of Abnormal Child Psychology, 28, $205-211$.

Brown, T. A., Chorpita, B. F., \& Barlow, D. H. (1998). Structural relationships among dimensions of the DSM-IV anxiety and mood disorders and dimensions of negative affect, positive affect, and autonomic arousal. Journal of Abnormal Psychology, 107, 179-192. 
Chorpita, B. F., Albano, A. M., \& Barlow, D. H. (1996). Cognitive processing in children: Relation to anxiety and family influences. Journal of Clinical Child Psychology, 25, 170-176.

Chorpita, B. F., Plummer, C. M., \& Moffitt, C. E. (in press). Relations of tripartite dimensions of emotion to childhood anxiety and mood disorders. Journal of Abnormal Child Psychology.

Clark, L. A., \& Watson, D. (1991). Tripartite model of anxiety and depression: Psychometric evidence and taxonomic implications. Journal of Abnormal Psychology, 100, 316-336.

Daleiden, E. L., \& Vasey, M. W. (1997). An information-processing perspective on childhood anxiety. Clinical Psychology Review, 17, 407-429.

De Wit, C. A. M. (1987). Depressie-vragenlijst voor kinderen (depression questionnaire for children). Amersfoort, The Netherlands: Acco.

Ginsburg, G. S., La Greca, A. M., \& Silverman, W. K. (1998). Social anxiety in children with anxiety disorders: Relation with social and emotional functioning. Journal of Abnormal Child Psychology, 26, 175-185.

Hadwin, J., Frost, S., French, C. C., \& Richards, A. (1997). Cognitive processing and trait anxiety in typically developing children: Evidence for interpretation bias. Journal of Abnormal Psychology, 106, 486-490.

Kendall, P. C. (1985). Toward a cognitive-behavioral model of child psychopathology and a critique of related interventions. Journal of Abnormal Child Psychology, 13, 357-372.

La Greca, A. M., Dandes, S. K., Wick, P., Shaw, K., \& Stone, W. L. (1988). Development of the social anxiety scale for children: Reliability and concurrent validity. Journal of Clinical Child Psychology, 17, 84-91.

La Greca, A. M., \& Stone, W. L. (1993). Social anxiety scale for children-revised: Factor structure and concurrent validity. Journal of Clinical Child Psychology, 22, 17-27.

Last, C. G., Strauss, C. C., \& Francis, G. (1987). Comorbidity among childhood anxiety disorders. Journal of Nervous and Mental Disease, 175, 726-730.

Last, C. G., Hersen, M., Kazdin, A. E., Finkelstein, R., \& Strauss, C. C. (1987). Comparison of DSM-III separation anxiety and overanxious disorders: Demographic characteristics of patterns of comorbidity. Journal of the American Academy of Child and Adolescent Psychiatry, 26, 527-531.

MacLeod, A. K., \& Byrne, A. (1996). Anxiety, depression, and the anticipation of future positive and negative experiences. Journal of Abnormal Psychology, 105, 286-289.

Meijer, P. G., Mellenbergh, G. J., \& De Wit, C. A. M. (1986). De Korte Depressie-vragenlijst voor kinderen (the short depression questionnaire for children). Nederlands Tijdschrift voor Psychologie, 41, 364-368.

Muris, P., Kindt, M., Bögels, S. M., Merckelbach, H., Gadet, B., \& Moulaert, V. (2000a). Anxiety and threat perception abnormalities in normal children. Journal of Psychopathology and Behavioral Assessment, 22, 183-199.

Muris, P., Merckelbach, H., \& Damsma, E. (2000b). Threat perception bias in nonreferred, socially anxious children. Journal of Clinical Child Psychology, 29, 348-359.

Ollendick, T. H., \& King, N. J. (1998). Empirically supported treatments for children with phobic and anxiety disorders: Current status. Journal of Clinical Child Psychology, 27, 156-167.

Spielberger, C. D. (1973). Manual for the state-trait anxiety inventory for children. Palo Alto, CA: Consulting Psychologists Press.

Stallings, P., \& March, J. S. (1995). Assessment. In J. S. March, Anxiety disorders in children and adolescents (pp. 125-147). New York: Guilford.

Teasdale, J. D. (1983). Negative thinking in depression: Cause, effect, or reciprocal relationship? Advances in Behaviour Research and Therapy, 5, 27-49.

Watson, D., Clark, L. A., \& Carey, G. (1988). Positive and negative affect and their relationship to anxiety and depressive disorders. Journal of Abnormal Psychology, 97, 346-353. 